$\S=-1$

\title{
Cloud Computing Adoption among Higher Education Institutions in Yemen: An Integrated Conceptual Framework
}

\author{
${ }^{1}$ Abdulnoor Saleh, ${ }^{2}$ Sulfeeza Mohd Drus, ${ }^{3}$ Siti Salbiah M. Shariff \\ ${ }^{1}$ Institute of Informatics and Computing in Energy \\ ${ }^{2}$ College of Computer Science and Information Technology \\ ${ }^{3}$ Universiti Tenaga Nasional (UNITEN), Malaysia. \\ *Corresponding author E-mail: abdulnoor_alshamery7@hotmail.com
}

\begin{abstract}
Researches in technology adoption among the Middle Eastern countries are more concentrated on e-government, e-commerce, and internet banking domains. Higher education institutions (HEIs) in these countries fall behind their Western counterparts due to the cutting edge technology adopted for research, teaching, and collaboration in the Western countries. One of the Middle Eastern countries, which is the focus of this research, Yemen, still adopt the conventional way of teaching in the HEIs, which could result in failures to accomplish the optimal desired educational performance. Higher education sector in Yemen faces a number of obstacles and challenges in delivering a good education to its entire population in terms of lack of reliable infrastructure; limited financial resources; lack of teaching staff and expertise; and lack of IT personnel to manage the existing restricted IT infrastructure. Cloud computing, a pool of computer-related resources and services, is seen as one of new technologies which can assist in improving educational delivery in Yemen. Thus, this study firstly, identified the factors that influence the cloud computing adoption in general. Then, it categorized these factors into four (4) domains, namely technological, organizational, environmental and individual domains; and lastly, validated the selected factors using semi-structured interview with IT experts. Based on the validation session with the IT experts, the factors were ranked based on their applicability and suitability in Yemeni's higher education environments and 13 factors were selected. These 13 factors are adopted from Technology Acceptance Model (TAM), Theory of Reasoned Action (TRA), Technology-Organization-Environment (TOE) framework and Diffusion of Innovation (DOI) theory. Then, a conceptual framework was developed using these 13 factors to identify the significant factors that influence cloud computing adoption in HEIs in Yemen. It is hoped by having a better understanding on the factors that influence cloud computing adoption in HEIs in Yemen, the responsible parties such as the government agencies, HEIs managements and staff will be more prepared to ensure successful adoption of cloud computing in their HEIs and ultimately help Yemen to improve its higher education delivery to its people.
\end{abstract}

Keywords: Cloud computing, educational cloud, higher education institution, individual theory, organizational theory.

\section{Introduction}

The education system has a symbiotic relationship with technology, and has been the basis for many technological innovations. On the other hand, technology has also played an essential role in the evolution of education. In particular, IT has played an important role in making education more interactive and collaborative among the learners and educators. In today's education system, educators and students use technology in many aspects such as for classroom teaching; online educational materials such as books and journals; online forums; and online assessments such as examinations, assignments, quizzes and tests. Similarly, in addition to using technology for teaching and learning purposes, higher education institutions (HEIs) also use technology for managing the admission process; managing the students and staff records; as well as creating the education content.

In HEIs, cloud computing provides agility to host educational applications; thus enables educators to build content with multiple level of difficulties for beginner, intermediate and advanced levels, without worrying about the technical requirements and configurations. Instead, there can just be one application for different web operating systems [1]. As such, by implementing cloud computing, HEIs do not need to be concerns of any maintenance and technical issues, such as installation and networking, which could impede the educational process and delivery $[2,3]$.

Educational cloud is considered as one of the most interesting cloud applications [4-6]. Educational cloud utilizes the power of thousands of computers on solving a same set of problems and allows fellow researchers from multiple HEIs to collaborate and conduct their research works. In addition, HEIs can open their cloud computing infrastructures to be used by both public and private sectors for research advancement. The efficacy of cloud computing can assist HEIs to keep pace with the growing IT resources requirements and at the same time can minimize spending on infrastructure and energy related costs.

In the 21st Century, developing countries are facing lots of pressure from international organizations and businesses such as the World Bank to alleviate the use of information and communication technology (ICT) in the attempt to reduce the effect of digital divide [7]. In alignment with this perspective, 
Yemen, as one of the developing countries, is also looking at the possibility of adopting ICT solutions and services in ensuring that education can be reached and offered to its entire citizen.

Due to the growth of cloud computing adoption, the factors that influence the IT professionals in adopting cloud computing may need to be understood better. This could help organizations to really understand the motivations behind these adoptions. This study is focusing on the IT professionals working in HEIs in Yemen, including IT support staff as well IT lecturers, to assess their readiness in adopting cloud computing in their job functions From the review of the literature, it can be observed that there are a number of studies that focus on cloud computing adoption at organizational level, but a limited number of studies are conducted at looking cloud computing adoption at individual level.

This study aims at integrating these two perspectives, by incorporating the factors from individual-level and organizationallevel theories and assess whether these factors influence IT professional towards cloud computing adoption in their organizations. The integration of individual-level and organizational-level theories offer a more comprehensive perspective that could help in better predicting and explaining the adoption behaviors, thus could facilitate the management of these HEIs to plan and strategize their IT related investments. The following section discusses a number of individual-level and organizational-level theories related to ICT innovation adoption.

\section{Theories of ICT Innovation Adoption}

Adoption is defined as a decision to start something for instance a plan, idea or new technology [8]. The adoption process is a sequence of stages before the acceptance the new plan, idea, service, product, or technology. The stages start by getting some preliminary knowledge of the innovation; then, forming attitude towards the innovation; next, deciding to reject or adopt the innovation; then, implement the new innovation, and lastly, confirm the decision [8].

The adoption theories in the literature can be categorized at two (2) different units of analyses: a) individual (micro) level, and b) organizational (macro) level. At the individual or micro level, a number of theories related to technology adoption and acceptance can be found in the literature. [9] have discussed eight (8) individual-level technology adoption models and theories. The main objective of these individual-level theories and models is to determine the factors that affect an individual user's adoption of technology as well their usage behavior [10]. Thus, it can be presumed the theories at the individual level focus on individuals' perceptions, behaviors and attitudes towards adoption of new technology or innovations. Among the most common individuallevel technology adoption theories and models include Theory of Reasoned Action (TRA); Technology Acceptance Model (TAM); Unified Theory of Acceptance and Use of Technology (UTAUT); Theory of Planned Behavior (TPB); Model of PC Utilization (MPCU); Motivational Model (MM); and Combined TAM and TPB (C-TAM-TPB). In addition, [11] indicate that besides Theory of Reasoned Action (TRA); Technology Acceptance Model (TAM); and Theory of Planned Behavior (TPB); and Unified Theory of Acceptance and Use of Technology (UTAUT); another model that is employed in studying individuals' ICT adoption and post-adoption behaviors is the Technology Acceptance Model 2 (TAM2).

On the other hand, the organizational-level theories are those theories that view technology adoption at the wider and bigger perspective such as from the community or business entity's perspective as a unit, and focus more on social process, social structure and their interrelationship. Among the common organizational-level theories in technology adoption include Technology-Organization-Environment (TOE) framework and Diffusion of Innovation (DOI) theory. Table 1 illustrates the technology adoption theories and models, at both individual and organizational levels.

Table 1: Technology Adoption Theories.

\begin{tabular}{|l|l|c|}
\hline Level of analysis & \multicolumn{1}{|c|}{ Name of Theory/Framework/Model } & Author \\
\hline \multirow{5}{*}{ Individual } & Theory of reasoned action (TRA) & {$[12]$} \\
\cline { 2 - 3 } & Theory of planned Behavior (TPB) & {$[13]$} \\
\cline { 2 - 3 } & Technology Acceptance Model (TAM) & {$[14]$} \\
\cline { 2 - 3 } & $\begin{array}{l}\text { Unified Theory of Acceptance and Use } \\
\text { of Technology (UTAUT) }\end{array}$ & {$[9]$} \\
\cline { 2 - 3 } Organization & Model of PC Utilization (MPCU) & {$[15]$} \\
\cline { 2 - 3 } & Motivational Model (MM) & {$[16]$} \\
\cline { 2 - 3 } & Self-efficacy theory (SE) & {$[18]$} \\
\hline & $\begin{array}{l}\text { Technology-Organization-Environment } \\
\text { (TOE) }\end{array}$ & $\begin{array}{l}\text { Theory on Diffusion of Innovation } \\
\text { (DOI) }\end{array}$ \\
\hline
\end{tabular}

\section{Methodology}

The objective of this study is to develop a conceptual framework by identifying the factors that influence cloud computing adoption in HEIs by integrating Technology Acceptance Model (TAM), Theory of Reasoned Action (TRA), Technology-OrganizationEnvironment (TOE) framework and Diffusion of Innovation (DOI) theory. Firstly, the factors that influence cloud computing adoption in general were identified through reviewing the existing literature. Based on the systematic literature review, 50 papers were shortlisted. Then, the factors that are discussed in these 50 papers were extracted and categorized into four (4) domains, namely technological, organizational, environmental and individual domains. Lastly, these factors were validated by Yemeni IT experts to assess the suitability and applicability of these factors in assessing the Yemeni's higher education environment. The validation was done through semi-structured interview whereby each factor was rated by the IT experts using a rating scale as shown in Table 2. Based on the validation done, 13 factors from TAM-TRA-TOE-DOI theory are selected and conceptual framework was developed.

Table 2: Rating of factors

\begin{tabular}{|c|c|}
\hline Factors Level of Significance & Interpretation \\
\hline Type 1 & $\begin{array}{c}\text { Not very important but should be } \\
\text { noted }\end{array}$ \\
\hline Type 2 & Important \\
\hline Type 3 & Critical \\
\hline
\end{tabular}

\section{The Proposed Conceptual Framework}

Based on the literature performed, it has shown and justified the significant importance of explaining technology adoption from both individual-level and organizational-level perspectives. Based on this presumption, this study combines both individual-level and organizational-level theories in understanding the factors that could affect the cloud computing adoption in HEIs in Yemen.

These factors are classified into four (4) dimensions, namely: i) technological; ii) organizational; iii) environmental; and lastly, iv) individual. The identified factors were adopted from four (4) main adoption theories, which are Technology Acceptance Model (TAM); Theory of Reasoned Action (TRA); Diffusion of Innovation (DOI) theory; Technology, Organization, Environment (TOE) framework. Table 4 describes the factors in each of these dimensions. 
Table 3: Factors affecting cloud computing adoption in higher education in Yemen

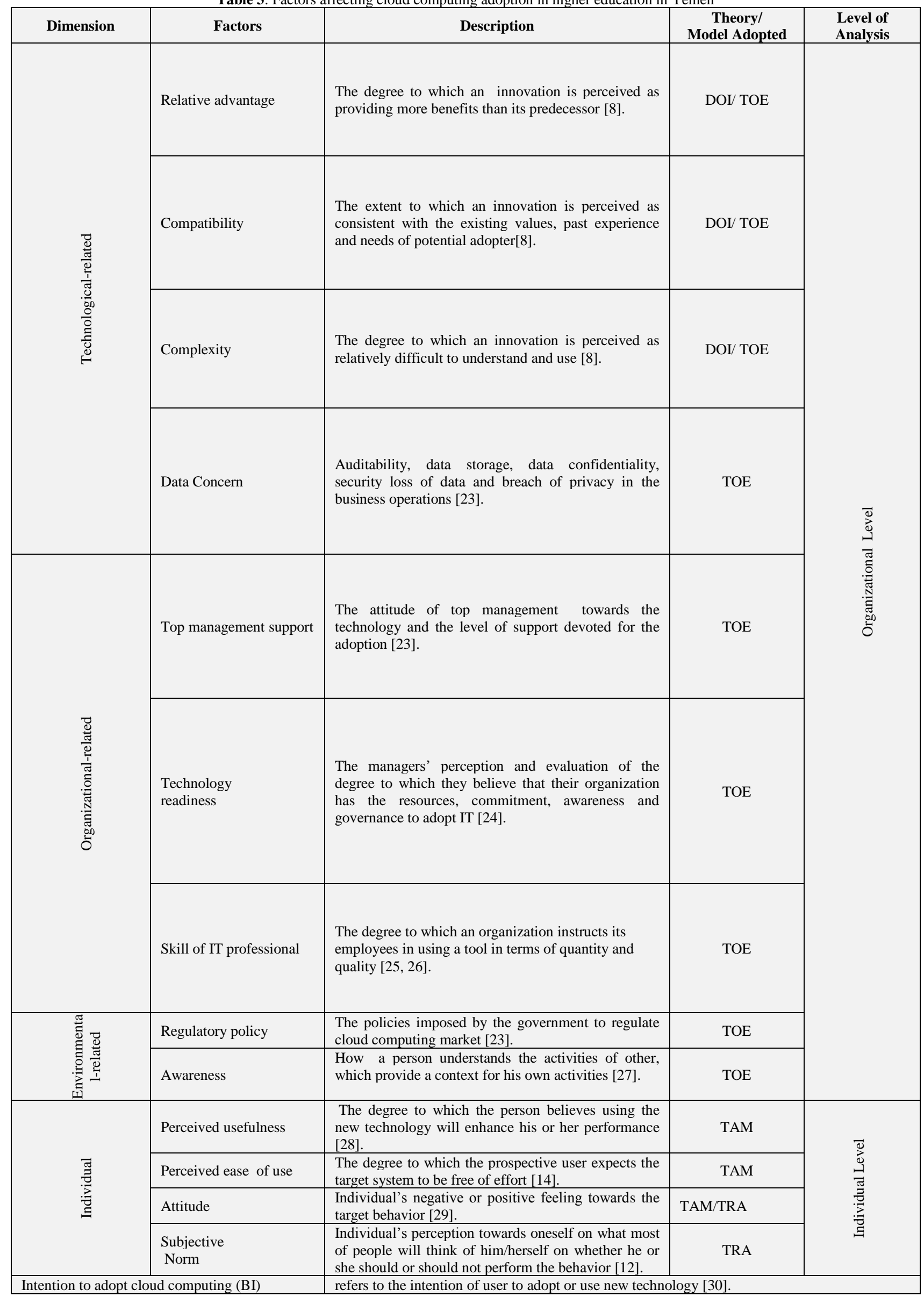


Based on the selected factors as elaborated in Table 3, this study has identified 22 hypotheses to measure and assess the impact of each factor on the intention of higher education in
Yemen to adopt cloud computing (as illustrated in Table 4). The conceptual framework that is proposed for this study based on the identified hypotheses is shown in Figure 1.

Table 4: Hypotheses based on the significant factors of cloud computing adoption

\begin{tabular}{|c|c|c|}
\hline Variable & Factor & Hypotheses \\
\hline \multirow{12}{*}{ 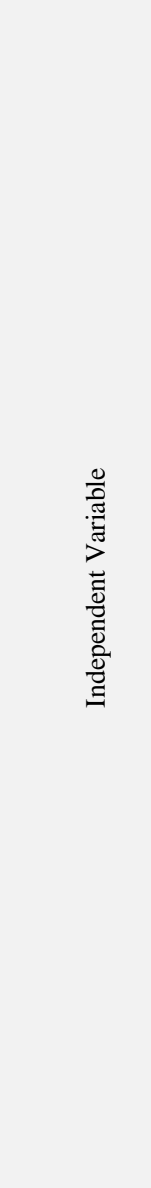 } & Relative Advantage & $\begin{array}{l}\text { +H1a: Relative advantage has a positive effect on PU } \\
+ \text { H1b: Relative advantage has a positive effect on PEOU }\end{array}$ \\
\hline & Compatibility & $\begin{array}{l}+\mathrm{H} 2 \mathrm{a} \text { : Compatibility has a positive effect on PU } \\
+\mathrm{H} 2 \mathrm{~b} \text { : Compatibility has a positive effect on PEOU }\end{array}$ \\
\hline & Complexity & $\begin{array}{l}\text {-H3a: Complexity has a negative effect on PU } \\
\text {-H3b: Complexity has a negative effect on PEOU }\end{array}$ \\
\hline & Data Concern & $\begin{array}{l}\text {-H4a: Data Concern has a negative effect on PU } \\
\text {-H4b: Data Concern has a negative effect on PEOU }\end{array}$ \\
\hline & $\begin{array}{l}\text { Top Management } \\
\text { Support }\end{array}$ & $\begin{array}{l}\text { +H5a: Top management support has a significant effect on PU } \\
\text { +H5b: Top management support has a significant effect on PEOU }\end{array}$ \\
\hline & $\begin{array}{l}\text { Technology } \\
\text { Readiness }\end{array}$ & $\begin{array}{l}\text { +H6a: Technology Readiness has a significant effect on PU } \\
\text { +H6b: Technology Readiness has a significant effect on PEOU }\end{array}$ \\
\hline & $\begin{array}{l}\text { Skill Of IT } \\
\text { Professional }\end{array}$ & $\begin{array}{l}+\mathrm{H} 7 \mathrm{a}: \text { Skill of IT has significant effect on PU } \\
+\mathrm{H} 7 \mathrm{~b}: \text { Skill of IT has significant effect on PEOU }\end{array}$ \\
\hline & Regulatory Policy & -H8: Regulatory policy has a negatively affect on behavioral intention of cloud computing adoption \\
\hline & Awareness & $+\mathrm{H} 9$ : Awareness is positively correlated with Behavioral intention of cloud computing adoption \\
\hline & Perceived Usefulness & + H10. PU has positively influences attitudes towards behavioral intention to adopt cloud computing \\
\hline & $\begin{array}{l}\text { Perceived Ease Of } \\
\text { Use }\end{array}$ & $\begin{array}{l}\text { +H11a. PEOU has positive effect on attitudes towards behavioral intention to adopt cloud computing } \\
\text { +H11b. PEOU has positive effect on PU }\end{array}$ \\
\hline & Attitude & H12. Attitude positively affects the behavioral intention to adopt cloud computing \\
\hline 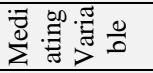 & Perceived Usefulness & $\begin{array}{l}\text { H13. Perceived Usefulness (PU) mediates the relationship between Perceived Ease of Use (PEU) and } \\
\text { Attitude (ATT) }\end{array}$ \\
\hline 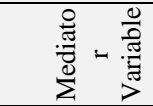 & Subjective Norm & $\begin{array}{l}\text { H14. A Subjective Norm (SN) moderates the influence of perceived Usefulness (PU) on attitude } \\
\text { towards e behavioral intention to adopt cloud computing. }\end{array}$ \\
\hline
\end{tabular}

As illustrated in Figure 1, the conceptual framework of this study consists of a) nine (9) independent variables, namely relative advantage, compatibility, complexity, data concern, top management support, technology readiness, skill of IT professional, regulatory policy, and awareness; b) one(1) mediating variables, which is perceived usefulness; and c) one (1) mediator, which is subjective norm. 


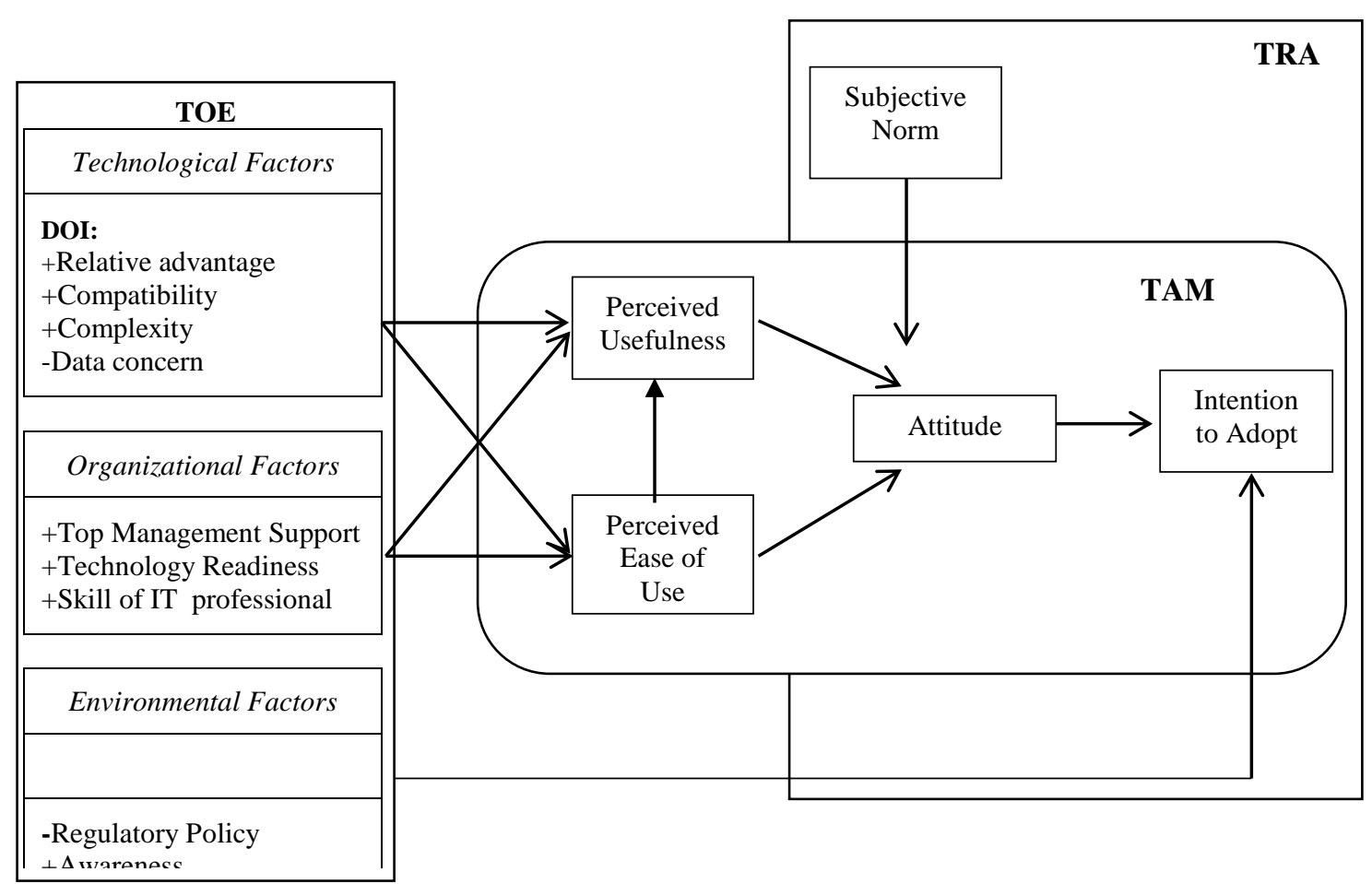

Figure 1: The proposed conceptual framework.

Through evaluating the hypotheses identified in the conceptual framework, it is hoped that the needs and perspectives of HEIs in Yemen could be addressed and understood better in enhancing the level of technology adoption in its education institution in the attempt to increase the delivery and accessibility of higher education to its citizen.

\section{Conclusion and Future Works}

This paper has discussed the needs for a new technological approach in the education system for developing countries, such as Yemen. It is seen that public cloud is the most suitable platform to be adopted by higher educational institutions (HEIs) in developing countries due to the low initial investments as well as minimal operating costs. Nevertheless, the understanding on the factors that may affect the adoption of cloud computing is needed to be undertaken prior to the actual implementation of cloud computing platform in the HEIs.

The first stage of this study was performed in classifying and categorizing the factors that affect cloud computing adoption into four (4) domains, namely technological, organizational, environmental, and individual. Then, based on interview guideline from study of [19], semi-structured interview method was adapted by targeting the Yemeni IT experts in Malaysia in identifying the significant factors as seen suitable for the higher education environment in Yemen. This is the main discussion in this paper.

Next, this study will embark on the second stage, whereby a quantitative approach will be adopted. According to [20] " use of quantitative is rooted in the positivist world view of determinism, where causes where determine effects or out comes". The use of quantitative approach is to validate the relationships between the independent variables and dependent variable, which is the intention to adopt cloud computing. [20] mentions that the relationship between variables can only be studied in a nonexperimental research design using quantitative data. The population will be the employees in HEIs under the Ministry of Higher Education and Ministry of Technical Education and Vocational Training in Yemen. The sample size of this research will target the professional IT, IT manager, and lecturer of IT in higher education institutions. It is hoped by having a better understanding on the factors that influence cloud computing adoption in HEIs in Yemen, the responsible parties such as the government agencies, HEIs managements and staff will be more prepared to ensure successful adoption of cloud computing in their HEIs and ultimately help Yemen to improve its higher education delivery to its people.

\section{Acknowledgements}

The authors would like to thank Institute of Informatics and Computing in Energy (IICE), UNITEN; and College of Computer Science and Information Technology (CSIT) UNITEN for the assistance and opportunities. In addition, the authors would also like to extend their gratitude to Ministry of Higher Education and Ministry of Technical Education and Vocational Training in Yemen for their support.

\section{References}

[1] Lawton, G., Moving the OS to the Web. IEEE Computer, 2008. 41(3): p. 16-19.

[2] Ivica, C., J.T. Riley, and C. Shubert. StarHPC-Teaching parallel programming within elastic compute cloud. in Information Technology Interfaces, 2009. ITI'09. Proceedings of the ITI 2009 31st International Conference on. 2009. IEEE.

[3] Vaquero, L.M., EduCloud: PaaS versus IaaS cloud usage for an advanced computer science course. IEEE Transactions on Education, 2011. 54(4): p. 590-598.

[4] Biswas, S. HOW CAN CLOUD COMPUTING HELP IN EDUCATION? 2011; Available from: http://cloudtweaks.com/2011/02/how-can-cloud-computing-helpin-education/.

[5] Morrill, D. Cloud Computing in Education. 2011; Available from: https://www.cloudave.com/14857/cloud-computing-in-education/.

[6] Mircea, M. and A.I. Andreescu, Using cloud computing in higher education: A strategy to improve agility in the current financial crisis. Communications of the IBIMA, 2011.

[7] Avgerou, C., Information systems in developing countries: a critical research review. Journal of information Technology, 2008. 23(3): p. 133-146. 
[8] Rogers, E., Diffusion of Innovations. New York. A Division of Simon \& Schuster. 1995, Inc.

[9] Venkatesh, V., et al., User acceptance of information technology: Toward a unified view. MIS quarterly, 2003: p. 425-478.

[10] Oly Ndubisi, N. and M. Jantan, Evaluating IS usage in Malaysian small and medium-sized firms using the technology acceptance model. Logistics Information Management, 2003. 16(6): p. 440450.

[11] Kim, J., et al., Training soft skills via e-learning: international chain hotels. International Journal of Contemporary Hospitality Management, 2011. 23(6): p. 739-763.

[12] Ajzen, I. and M. Fishbein, Belief, attitude, intention and behavior: An introduction to theory and research. 1975, Reading, MA Addison-Wesley.

[13] Ajzen, I., The theory of planned behavior. Organizational Behavior and Human Processes, 50, 179-211. 1991.

[14] Davis, F.D., R.P. Bagozzi, and P.R. Warshaw, User acceptance of computer technology: a comparison of two theoretical models. Management science, 1989. 35(8): p. 982-1003.

[13] Thompson, R.L., C.A. Higgins, and J.M. Howell, Personal computing: toward a conceptual model of utilization. MIS quarterly, 1991: p. 125-143.

[16] Davis, F.D., R.P. Bagozzi, and P.R. Warshaw, Extrinsic and intrinsic motivation to use computers in the workplace1. Journal of applied social psychology, 1992. 22(14): p. 1111-1132.

[17] Bandura, A., Self-efficacy: toward a unifying theory of behavioral change. Psychological review, 1977. 84(2): p. 191.

[18] Tornatzky, L., J. Eveland, and M. Fleischer, Technological innovation as a process. The Processes of Technological Innovation, Lexington Books, Lexington, MA, 1990: p. 27-50.

[19] Alshamaila, Y., S. Papagiannidis, and F. Li, Cloud computing adoption by SMEs in the north east of England: A multi-perspective framework. Journal of Enterprise Information Management, 2013. 26(3): p. 250-275.

[20] Creswell, J.W., Research design: Qualitative, quantitative, and mixed methods approaches. 2013: Sage publications.

[21] Abdulnoor Saleh, S.M.D., Siti S. M. Shariff, EMPRICAL STUDIES ON CLOUD COMPUTING ADOPTION: A SYSTEMATIC LITERATURE REVIEW JOURNAL OF THEORETICAL AND APPLIED INFORMATION TECHNOLOGY, 2017.

[22] Leedy, P.D. and J.E. Ormrod, Practical research. 2005: publisher not identified.

[23] Tashkandi, A.N. and I.M. Al-Jabri, Cloud computing adoption by higher education institutions in Saudi Arabia: an exploratory study. Cluster Computing, 2015. 18(4): p. 1527-1537.

[24] Tan, J., K. Tyler, and A. Manica, Business-to-business adoption of eCommerce in China. Information \& management, 2007. 44(3): p. 332-351.

[25] Mehrotra, A., Implementing IT in SCM-Understanding the Challenges. Global Business Review, 2010. 11(2): p. 167-184.

[26] Pillania, R.K., State of organizational culture for knowledge management in Indian industry. Global Business Review, 2006. 7(1): p. 119-135

[27] Dourish, P. and V. Bellotti. Awareness and coordination in shared workspaces. in Proceedings of the 1992 ACM conference on Computer-supported cooperative work. 1992. ACM.

[28] Nasri, W. and L. Charfeddine, An exploration of facebook. com adoption in Tunisia using technology acceptance model (TAM) and theory of reasoned action (TRA). Interdisciplinary Journal of Contemporary Research in Business, 2012. 4(5): p. 948.

[29] Ajzen, I. and M. Fishbein, Understanding attitudes and predicting social behaviour. 1980.

[30] Seymour, L., W. Makanya, and S. Berrangé. End-users' acceptance of enterprise resource planning systems: An investigation of antecedents. in Proceedings of the 6th Annual ISOnEworld Conference. 2007. 